\title{
O uso de mapas conceituais em aulas de Cálculo
}

Claudete Cargnin

Rui Marcos de Oliveira Barros

\section{Resumo}

Este artigo apresenta, sucintamente, o relato de uso de mapas conceituais no ensino de Cálculo Diferencial e Integral para um curso de engenharia ambiental. A elaboração do mapa conceitual permitiu, aos alunos, uma melhor compreensão da diferença entre os tipos de função, definição e elementos que envolvem o conceito de função, e, à professora, a constatação de equívocos no estudo do tema, como, por exemplo, a determinação do domínio e a relação entre os coeficientes e o aspecto gráfico de uma função, o que possibilitou a retomada de tais pontos em outros momentos da aula.

Palavras-chave:Mapa conceitual, Cálculo Diferencial e Integral, Função.

\begin{abstract}
This article presents, succinctly, a relate on the use of concept maps in teaching differential and integral calculus for an environmental engineering course. The elaboration of the conceptual map allowed, the students, a better understanding of the difference between the types of function, definition, and elements that involve the concept of function, and, the teacher, finding persistent misconceptions in the study on theme, as, for example, determining the domain and the relationship between the coefficients and the aspect graph of a function, which allowed the resumption of such points at other times of the lesson.
\end{abstract}

Keywords: concept maps, differential and integral calculus, function. 


\section{Introdução}

Há muito tempo a disciplina de Cálculo Diferencial e Integral (CDI) tem sido objeto de investigação para vários pesquisadores em todo o mundo. Nas últimas décadas intensificou-se a proposição de sequências didáticas a fim de facilitar a aquisição do conhecimento matemático. Entretanto, os problemas na aprendizagem em CDI permanecem, haja vista o grande número de reprovados nesta disciplina, nas mais diversas instituições de ensino superior.

Normalmente as dificuldades enfrentadas pelos estudantes universitários são justificadas, por eles e/ou por alguns educadores, com a argumentação de que não se gosta daquilo que não se entende. E se não gostam, não querem perder tempo estudando o assunto. Esse argumento pode justificar tais dificuldades, com relação às disciplinas da área de exatas, por estas serem abordadas, normalmente, em nível bastante formal e sem a preocupação com a aprendizagem do aluno. Santos e Borges Neto (2009) apontam a incapacidade cognitiva de aprender os conteúdos de Cálculo como uma das causas para os resultados adversos nesta disciplina. Porém, a utilização de mapas conceituais pode apontar justamente para a capacidade cognitiva do aluno para aprender tais conteúdos.

Silva et al (2006) acreditam que o uso de uma metodologia em que se enfatize a construção do conhecimento reflexivo, pode minimizar os diversos problemas detectados na aprendizagem dos conceitos matemáticos. A elaboração de mapas conceituais parece corroborar nessa reflexão.

Durante o estudo de algumas disciplinas cursadas no programa de pós-graduação em Educação para a Ciência e a Matemática, da Universidade Estadual de Maringá, percebi as dificuldades inerentes à elaboração de mapas conceituais, existe a exigência de análise e compreensão profunda do assunto em estudo, a fim de inserir nele as palavras e relações chave para a aprendizagem. Percebi, inclusive, que a releitura de um texto, ou discussão referente ao assunto, traz alterações enriquecedoras para o mapa conceitual elaborado, o que permite que ele possa ser usado como instrumento de avaliação da compreensão de um conceito.

Tem sido crescente a utilização de mapas conceituais no ensino, nas mais variadas áreas e com as mais diversas finalidades. Sua potencialidade permite seu uso tanto como instrumento de ensino, como a representação das estruturas conceituais de uma disciplina, quanto instrumento de avaliação, para perceber as relações que os alunos constroem dos conceitos em estudo.

Pensando nisso, iniciou-se uma investigação acerca da contribuição da elaboração de Mapas Conceituais para a aprendizagem de conteúdos referentes à disciplina de CDI. Neste artigo, em especial, será abordado o tema funções. 


\section{A utilização de mapas conceituais como acompanhamento do aprendizado}

O interesse em mapas conceituais surgiu com a utilização destes em uma das disciplinas cursadas na pós-graduação, naquela ocasião, utilizado como instrumento de avaliação. A elaboração de tal mapa exigiu estudo aprofundado e discussão dos temas estudados, fato que estimulou sua utilização com meus alunos de graduação, na disciplina de Cálculo Diferencial e Integral I (CDI), já que, geralmente, eles carregam dificuldades em conteúdos que são prérequisitos para boa compreensão dos assuntos pertinentes ao CDI. Mais à frente será detalhado o contexto de implementação.

Para Moreira (2006, p.45), “mapas conceituais são apenas diagramas que indicam relações entre conceitos" e que podem ser interpretados como "diagramas hierárquicos que procuram refletir a organização conceitual de uma disciplina ou parte dela".

Para Souza (s/d, p.5):

Os mapas conceituais favorecem a consecução de uma avaliação formativa, até porque eles permitem a compreensão da situação do aluno ao propiciar a identificação e análise dos erros, juntamente com a promoção de diagnóstico mais apurado do funcionamento cognitivo envolvido. Em decorrência, podem fornecer indicadores mais precisos ao professor para a recomposição do trabalho didático.

Num mapa conceitual, a estruturação hierárquica permite perceber tanto os desdobramentos de um determinado conceito (chamado de diferenciação progressiva) quanto a relações com outros conceitos (reconciliação integrativa), permitindo uma melhor aprendizagem para o aluno (TAVARES, 2007).

Um fator crucial na elaboração de mapas conceituais é a construção das frases de ligação entre os conceitos, que devem ser escritas de modo a representar a relação entre os conceitos que ela está ligando. Nas palavras de um aluno da Engenharia Ambiental sobre a elaboração de mapa conceitual: "a gente perde muito tempo procurando a frase certa pra ligar os conceitos". A elaboração de um mapa conceitual requer habilidades de escrita e síntese, além de um profundo conhecimento acerca do tema em estudo. Encontrar a expressão 'certa' para relacionar os conceitos, exige compreensão dos significados destes. Além disso, para estabelecer a reconciliação integrativa, que mostra a integração entre os diversos conceitos presentes, é preciso reflexão e estudo sobre o tema objeto do mapa.

Em relação aos benefícios da elaboração de mapas conceituais, Tavares (2007, p.74) argumenta:

R. B. E. C. T., vol 6, núm. 1, jan-abr.2013 ISSN - 1982-873X 
Quando um aprendiz utiliza o mapa durante o seu processo de aprendizagem de determinado tema, vai ficando claro para si as suas dificuldades de entendimento desse tema. Um aprendiz não tem muita clareza sobre quais são os conceitos relevantes de determinado tema, e ainda mais, quais as relações sobre esses conceitos. Ao perceber com clareza e especificidade essas lacunas, ele poderá voltar a procurar subsídios (livro ou outro material instrucional) sobre suas dúvidas, e daí voltar para a construção de seu mapa. Esse ir e vir entre a construção do mapa e a procura de respostas para suas dúvidas irá facilitar a construção de significados sobre conteúdo que está sendo estudado. $O$ aluno que desenvolver essa habilidade de construir seu mapa conceitual enquanto estuda determinado assunto, está se tornando capaz de encontrar autonomamente o seu caminho no processo de aprendizagem.

\section{0 contexto de implementação e os resultados obtidos}

Diante da decisão de tentar usar os Mapas Conceituais como instrumento de acompanhamento do aprendizado do aluno, ele foi estabelecido como parte da avaliação somativa da disciplina CDI, no primeiro semestre de 2012, para o curso de Engenharia Ambiental da Universidade Tecnológica do Paraná - UTFPR - campus Campo Mourão.

Inicialmente, como experiência, foi estipulado que um mapa conceitual que versasse sobre "Funções" deveria ser entregue no dia da primeira avaliação escrita regimental. A turma possuía, à época, 46 alunos e estes deveriam confeccionar tal mapa com a finalidade de estudar mais o assunto, perceber as relações entre os diferentes tipos de função, os detalhes da definição, reestudar os conteúdos do ensino médio e relacioná-los com os ministrados nas 20 primeiras aulas de CDI. Estabeleceu-se que o Mapa elaborado seria avaliado e, de acordo com as conexões dos conceitos abordados no mapa, Ihe seria atribuída uma nota entre zero e um, o que correspondia a um décimo da nota da avaliação .

Para tanto, inicialmente foi explicado à turma o que eram mapas conceituais, como era construído e qual a finalidade dele na disciplina. Embora os alunos não o conhecessem, se interessaram por fazer o "trabalho" sem maiores reclamações. Foi indicado o uso do software Cmap Tools para a sua elaboração, porém a forma de montagem e apresentação (entrega) foi deixada livre. Contudo, a quase totalidade dos alunos optou por aceitar tal indicação, pela facilidade no processo de criação do mapa nesta mídia, pois o aplicativo permite acesso rápido às frases de ligação e possui caracteres matemáticos. O produto final foi impresso e entregue no dia da avaliação regimental, como fora previsto.

Durante o decorrer das aulas sobre funções, o acompanhamento da elaboração dos mapas foi realizado (alguns momentos foram destinados especificamente para a discussão dos 
mapas entre os alunos e entre estes e a professora) e percebeu-se que os alunos que geralmente se mostravam mais interessados nas aulas, demonstraram maior preocupação em acrescentar informações sobre o tema no mapa e em saber se o estavam fazendo corretamente. Aqueles que não eram tão participativos em sala, também não se preocuparam com o mapa, mesmo tendo-o feito.

Um exemplo de um mapa conceitual elaborado pelo aluno A está na Figura 1.

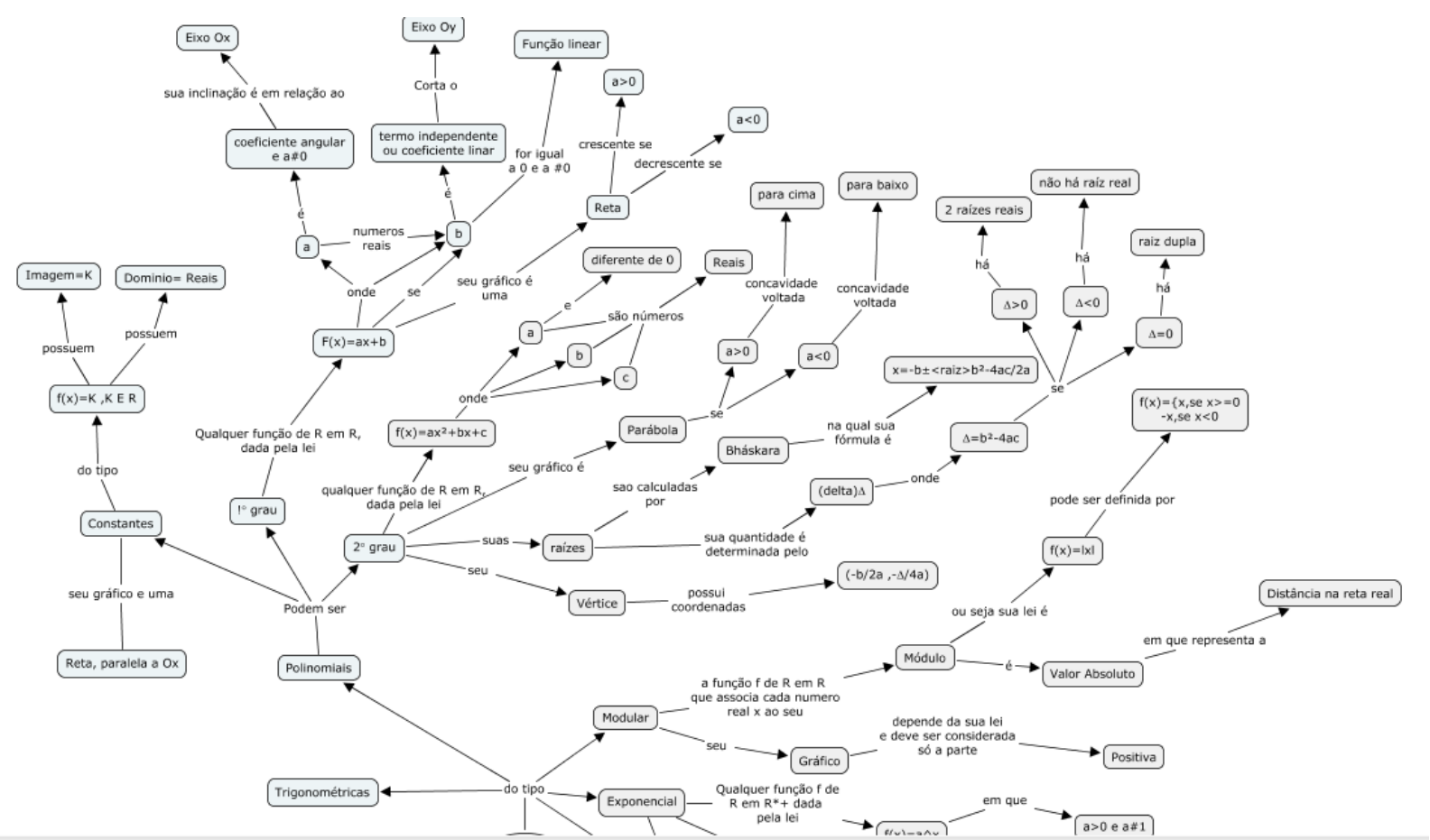

Figura 1. Mapa conceitual (parcial) elaborado por aluno do curso de Engenharia Ambiental sobre função.

O esquema apresentado na figura 1 retrata as ligações e conceitos considerados importantes para o estudo das funções, para o aluno A. Observe o nível de detalhamento das funções polinomiais de grau menor ou igual a dois, em detrimento da (não) informação acerca das funções trigonométricas. Isto pode indicar dificuldade de compreensão desse tipo de função para esse aluno.

A figura 2 apresenta parte de outro mapa elaborado pelo aluno B, especificando os tipos de função e suas características, segundo a visão do estudante, com as informações que ele considerou relevantes. 


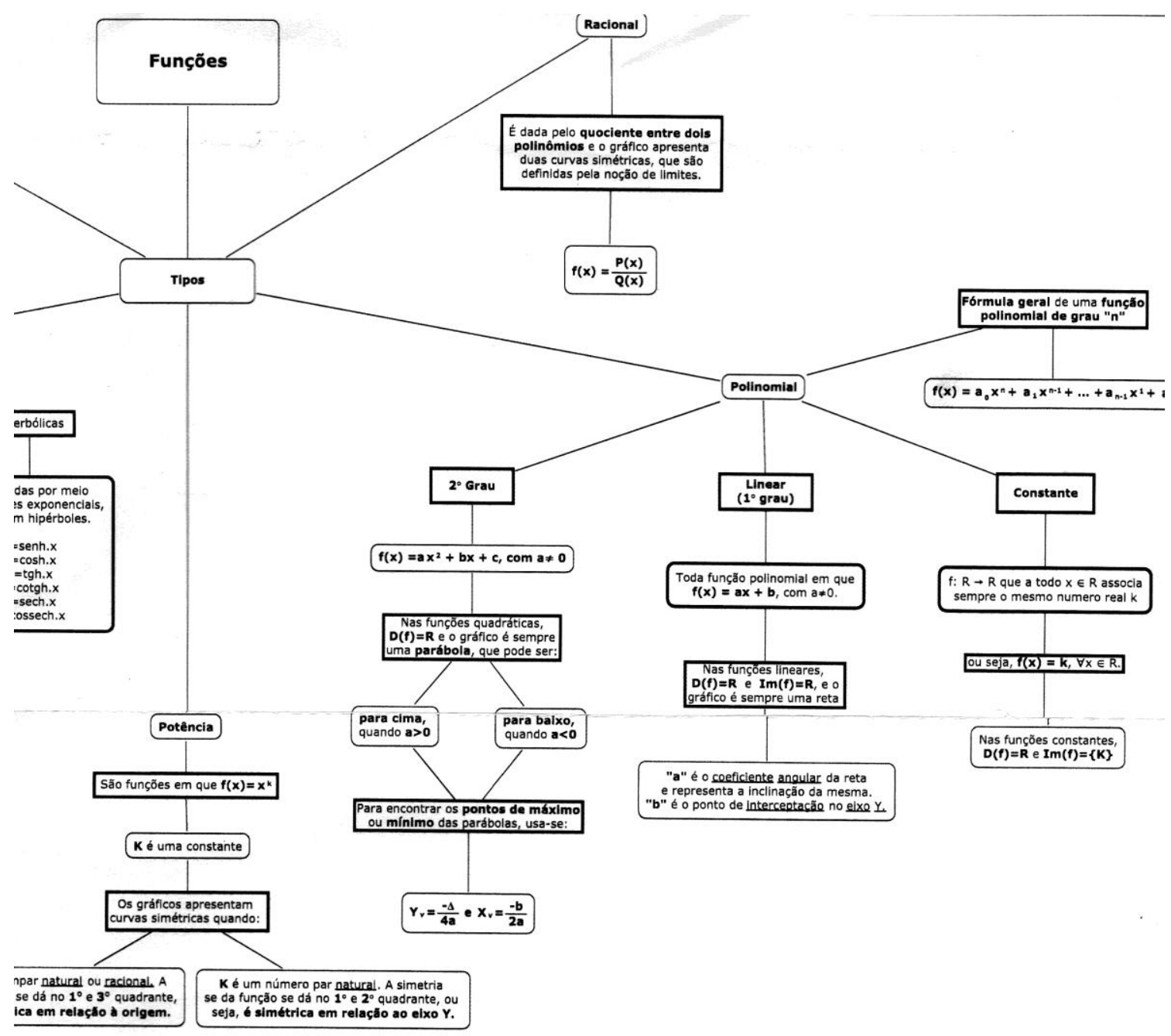

Figura 2: parte de um mapa conceitual elaborado por aluno do curso de Engenharia Ambiental sobre o tema função

O mapa da figura 3 fornece indicações sobre a percepção do aluno acerca dos prérequisitos de um estudo, o que, geralmente, mesmo sendo comentado pelo professor, nem sempre é percebido pelos alunos. O discente anotou a necessidade de conhecimentos básicos de aritmética e de noção de conjuntos numéricos para o entendimento das funções (ramo situado do lado esquerdo da figura). 


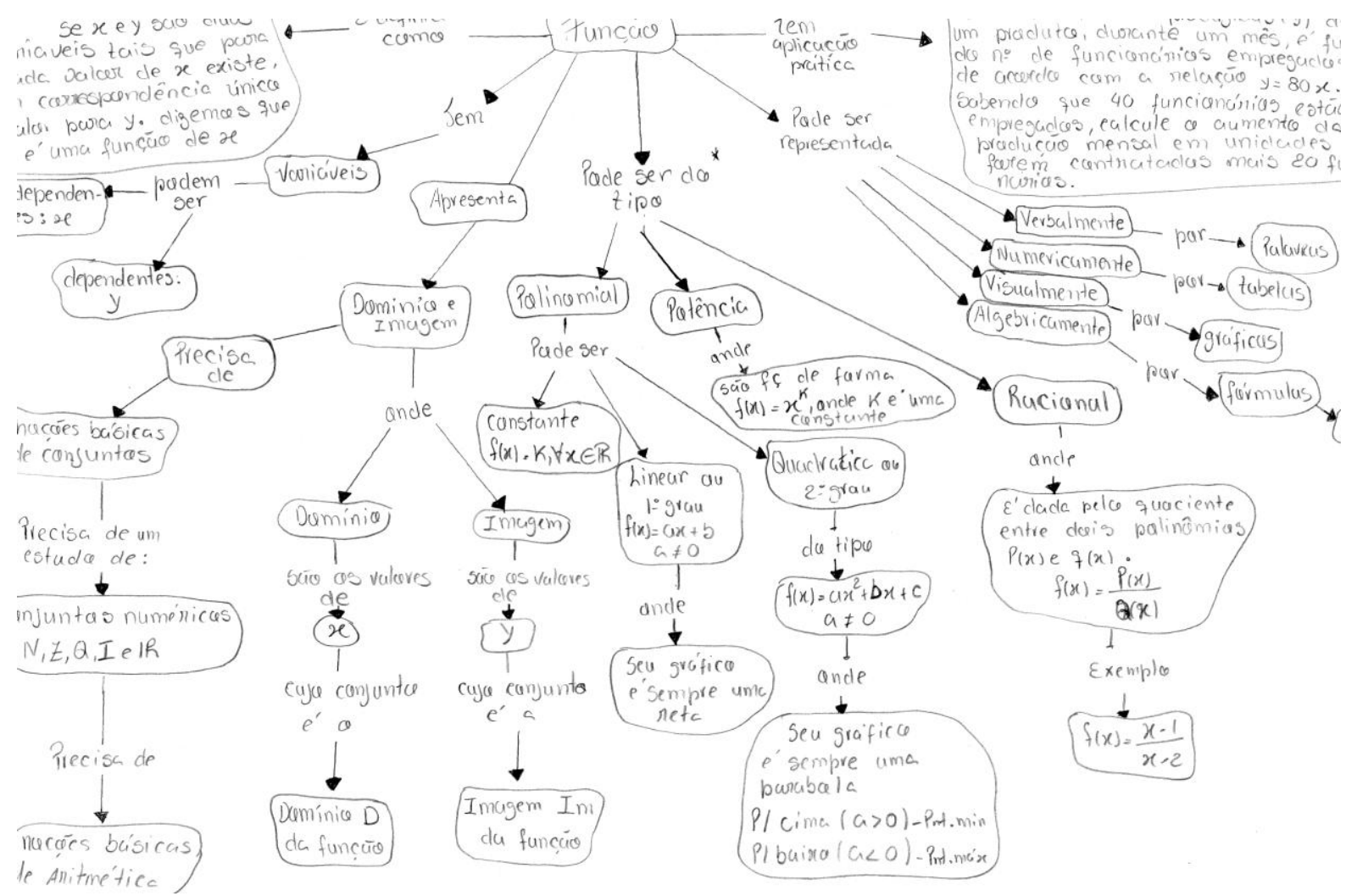

Figura 3: parte de um mapa conceitual elaborado por aluno do curso de Engenharia Ambiental sobre o tema função

Na literatura, encontra-se que, em relação a mapas conceituais, existe UM mapa e não O mapa, já que cada indivíduo põe o que lhe parece ser conveniente, o que mais the chamou a atenção, seja pela facilidade em aprender, seja pela dificuldade encontrada no estudo, e é justamente por isso que mapas conceituais são instrumentos importantes de acompanhamento da aprendizagem do aluno.

Nas Figuras 4 e 5 são apresentados dois mapas elaborados por uma mesma aluna, do curso de Engenharia Ambiental, mas que cursou a disciplina CDI no segundo semestre de 2012 (o valor atribuído ao mapa foi, em termos percentuais, igual ao do semestre anterior). 


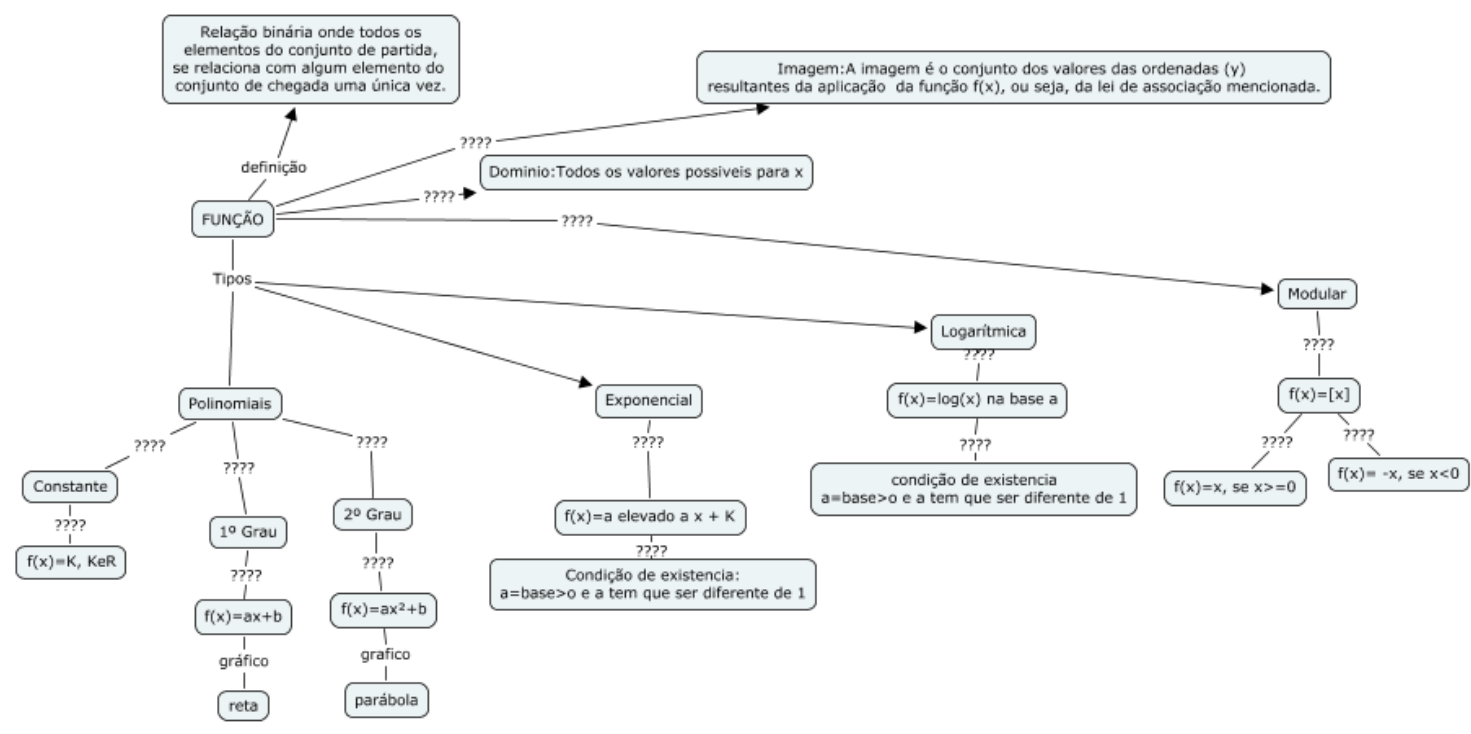

Figura 4: Mapa Conceitual inicial da aluna Z

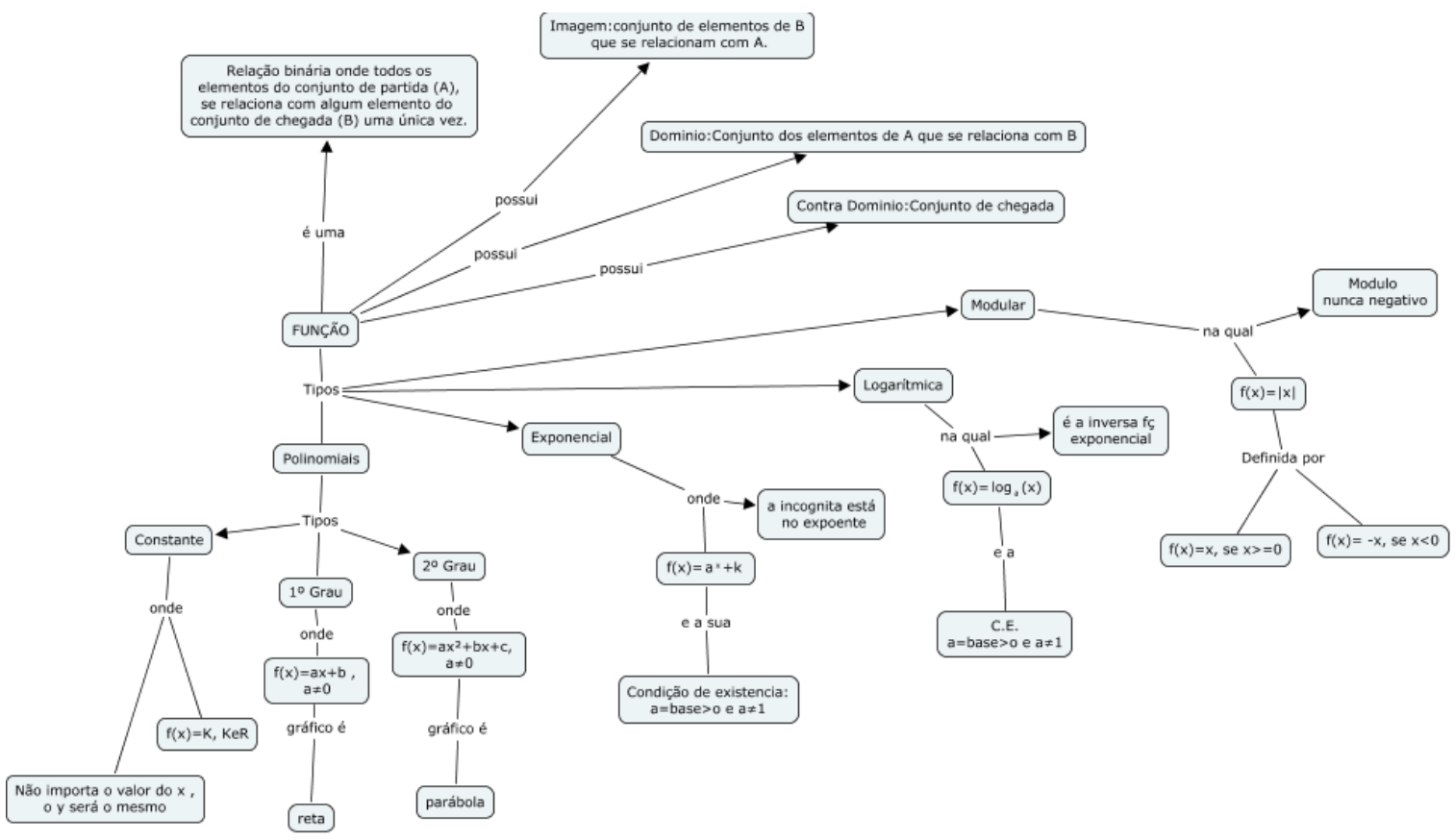

Figura 5: Mapa Conceitual revisado pela aluna Z após orientação docente

Observe, na figura 4, que a aluna não havia escrito frases de ligação entre os conceitos. Isto pode indicar que a referida discente apenas selecionou algumas das informações referentes ao conteúdo (aquelas que, provavelmente, foram escritas no quadro negro), mas não conseguiu identificar conexão entre elas. Mas também é possível que apenas a aluna não tenha entendido como estabelecer esta conexão. Após orientações sobre o significado destas frases e acerca dos conteúdos matemáticos envolvidos, realizados por meio virtual e em enfatizados em sala de aula, a aluna $Z$ alterou seu mapa conforme indicado na Figura 5, no qual também não aparecem os 
conceitos associados às funções trigonométricas, assim como na figura 1. Esta semelhança constante nos mapas sobre funções em dois semestres consecutivos pode indicar a necessidade de rever a metodologia de revisão deste assunto nas aulas de CDI.

$\mathrm{Na}$ avaliação escrita regimental sobre o tema, constava uma questão sobre a contribuição da construção do mapa conceitual para o seu aprendizado. Foi esclarecido que se tratava apenas de uma consulta sobre o uso dos mapas e que a manifestação de discordâncias acerca do uso não afetaria a pontuação geral da avaliação. De maneira geral, reconheceram vantagens na utilização dos mapas para a sua aprendizagem a respeito do tema. Algumas das respostas obtidas estão transcritas a seguir. (A codificação a seguir não tem relação com a das figuras anteriores).

Estudante A: "Para mim, foi muito bom elaborar esse mapa pois ao fazê-lo, além de memorizar as funções mais usuais como as funções polinomiais e as funções transcendentais, também me fez aprender aquelas não muito conhecida, como as hiperbólicas, $e$ as de arco seno, arco cosseno e arco tangente".

Estudante B: “... através dele foi necessário reler todo o conteúdo sobre funções, selecionar as partes mais importantes e organizá-lo visualmente, $e$ nesse modo mais resumido conseguir memorizar mais facilmente as características e tipos de cada função...".

Estudante C: "A vantagem de se fazer o mapa conceitual, é que, durante o processo, fazemos uma seleção de informações e temos mais visão da matéria".

Estudante D: "A vantagem que tirei muitas dúvidas ao ler a teoria novamente para fazer o mapa...".

Estudante E: "o mapa conceitual mostra-se como um instrumento bastante didático e, principalmente devido ao trabalho que se tem para elaborá-lo, acaba induzindo o sujeito que o elabora a se atentar para as informações mais importantes".

Estudante F: "o mapa conceitual é válido não só nas matérias de cálculo, mas em outras matérias também porque é como se fosse uma revisão para a prova".

Estudante G: "Mesmo sendo trabalhoso, considero sua realização de extrema importância, sendo possível assim utilizá-la em diversas outras etapas da disciplina de Cálculo, já que sua correta elaboração implica no estudo mais 
aprofundado das funções, funcionando como um forte instrumento de estudo e assimilação".

Os depoimentos descritos mostram o quanto pode ser vantajosa a utilização de mapas para a construção de conhecimento dos alunos, mesmo que esse conhecimento não seja traduzido em notas altas nas provas escritas regimentais.

A utilização dos mapas conceituais em sala de aula permitiu a reavaliar a metodologia de ensino adotada e, também, perceber, para cada aluno, quais conceitos não estavam devidamente ancorados e precisavam de revisão. Além disso, permitiu refletir sobre como elaborar uma avaliação escrita de modo que realmente sejam aferidos os conhecimentos adquiridos pelos alunos a respeito do tema em análise, incluindo neles os conceitos anteriores que já deveriam estar incutidos no estudante, e não o contrário. Esta foi uma oportunidade de reflexão e crescimento.

Da mesma forma que houve alunos que aprovaram o uso de mapas conceituais como instrumento de aprendizagem, houve aqueles que apresentaram ressalvas, como destacam os alunos seguintes:

Estudante H: "O mapa ajudou na hora de 'decorar' as fórmulas das funções porém, é mais fácil de se aprender fazendo exercícios e com a ajuda da professora do que pelo mapa."

Estudante I: "a dificuldade na hora de produzir o mapa foi que temos que associar cada função, vendo suas diferenças e particularidade".

Estudante J: "De nada vale saber a teoria e as características de cada função e de seus componentes, se no momento de aplicar esta teoria num problema matemático o usuário não souber como proceder".

Estudante K: "Acredito que não valeria a pena (confeccionar outros mapas, em outros momentos da disciplina) em função do tempo gasto (para a elaboração)".

Estudante L: "o mapa conceitual exige muito de quem está o fazendo, pois devemos saber diferenciar cada parte e ligá-lo no lugar correto, para que tenhamos uma boa ferramenta para lembrar das funções".

Observa-se que alguns comentários contrários ao uso de mapas fazem referência ao tempo despendido na sua elaboração e não na pouca ou falta de contribuição para o reforço do aprendizado de um tema. Contudo, importa destacar que esta foi a primeira elaboração de mapa conceitual por estes alunos, e, naturalmente, surgem dificuldades para mapear os conceitos e suas relações, o que acarreta gasto de tempo maior. 
Para o docente, o mapa conceitual permitiu (e permite!) acompanhar, quase em tempo real, as falhas na compreensão e conexões dos conceitos em estudo. Entretanto, para que ele realmente sirva ao propósito de acompanhamento da aprendizagem do aluno, o docente deve despender um tempo maior para a análise das elaborações discentes e orientações individualizadas, além de planejar uma revisão dos assuntos observados como entraves para o sucesso da aprendizagem em CDI.

\section{Considerações Finais}

A análise dos mapas entregues mostrou que os alunos, na sua maioria, conseguiram identificar os conceitos relevantes, mas tiveram dificuldades em estabelecer as frases de ligação entre os conceitos e quais deles deveriam constar no mapa. Também foi possível perceber as confusões entre os tipos de função, nomenclaturas, etc. Alguns mapas foram entregues com conceitos mal elaborados, o que me permitiu voltar ao assunto em sala de aula, a fim de esclarecê-los.

Em conversa com esses alunos sobre a utilização de mapas conceituais, os mesmos sugeriram que fosse novamente elaborado mapa, porém, com tempo maior para discussão entre eles, para compararem entre si e, se possível, usá-lo como fonte de consulta no dia da prova.

Desde o primeiro semestre de 2012 os mapas conceituais têm sido usados como instrumento de acompanhamento da aprendizagem em aulas de CDI e a sua utilidade tem sido constatada. No entanto, ainda há resistência, por parte do aluno, em elaborar um mapa conceitual, pela necessidade de reflexão, estudo e compreensão do assunto em tela. Parece que, quanto maior o nível de complexidade do conteúdo, maior a resistência, devido à obrigação de dedicação maior de tempo para cumprir tal tarefa.

Esta atividade com os mapas conceituais demonstrou que esta é uma ferramenta que pode ser muito útil para acompanhar o aprendizado do aluno, e para incentivar que o aluno leia outros materiais além do que é usado em sala de aula, mas que tem maior efeito quando o aluno já viu ou fez um mapa antes.

Esse retorno de informações advindo da leitura e discussão dos mapas construídos favorece a alteração da prática profissional no que diz respeito à dinâmica da sala de aula e da elaboração de avaliações escritas que exijam maior esclarecimento dos conceitos em detrimento da habilidade no uso de fórmulas e algoritmos de resolução de exercícios. Além disso, foi possível perceber que as discussões, em sala de aula, a respeito dos mapas elaborados, foram enriquecedoras tanto para os estudantes, quanto para o professor, que pôde aproveitar esse momento coletivo para descobrir os pontos que ainda precisariam ser retomados no conteúdo trabalhado, o que melhorou efetivamente a aprendizagem do Cálculo Diferencial e Integral.

R. B. E. C. T., vol 6, núm. 1, jan-abr.2013 ISSN - 1982-873X 


\section{BIBLIOGRAFÍA}

Cargnin, C.; Barros, R.M.O. O uso de Mapas Conceituais em aulas de Cálculo. Anais da II Jornada Brasileira do Grupo de Pesquisa Euro-Latino-Americano. Universidade Tecnológica Federal do Paraná. Ponta Grossa - PR, 2012.

Moreira, M.A. A teoria da aprendizagem significativa e sua implementação em sala de aula. Brasília: Editora Universidade de Brasília, 2006.

Souza, N. A.. Avaliando o mapa conceitual como instrumento avaliativo. Disponível em http://www.anped.org.br/reunioes/31ra/1trabalho/GT04-4751--Int.pdf Acesso em 24/01/12.

Tavares, R. Construindo Mapas Conceituais. Ciências \& Cognição - Revista interdisciplinar de estudos da cognição, Rio de Janeiro, v.12, p.72-85,2007. Disponível em http://cienciasecognicao.tempsite.ws/revista/index.php/cec/article/view/641/423

Claudete Cargnin: professora de matemática da UTFPR- Campus Campo Mourão e doutoranda do programa de pós-graduação em Educação para a Ciência e a Matemática da UEM. cargnin@utfpr.edu.br

Rui Marcos de Oliveira Barros: professor do departamento de matemática da Universidade Estadual de Maringá e docente do programa de pós-graduação em Educação para a Ciência e a Matemática.professorrui@gmail.com 